\title{
Effects of the Parenting Efficacy Improvement Program for mothers as primary caregivers of children with cerebral palsy under rehabilitation
}

\author{
Da-Jung Kim, Youn-Jung Kim* \\ College of Nursing Science, Kyung Hee University, Seoul, Korea
}

The purpose of this study was done to determine the effect of a Parenting Efficacy Improvement Program (PEIP) to mothers of cerebral palsy. To investigate the PEIP on parenting efficacy and parenting stress. 60 subjects were composed with experimental group $(n=30)$ and control group $(n=30)$. The study was performed in the rehabilitation ward and rehabilitation daytime ward of National Health Insurance Service Ilsan Hospital in Goyang, Gyeonggi-do, Korea. The data were analyzed by chi-square test, independent $t$-test, and two-way repeated analysis of variance design using IBM SPSS Statistics ver. 20.0. Experimental group showed significantly improved parenting efficacy than that of control group $(F=295.79, P<0.001)$ and experimental group showed significant decrease parenting stress than that of control group $(F=138.76$, $P<0.001)$. The effect of a PEIP in this study was certainly improve parenting efficacy, decreased the parenting stress of cerebral palsy patient's mothers. This program can be deployed as a proper nursing intervention on mothers of patients with cerebral palsy.

Keywords: Cerebral palsy, Parenting efficacy, Parenting stress

\section{INTRODUCTION}

Cerebral palsy refers to a clinical syndrome that manifests as motor and postural impairments attributed to nonprogressive lesions or injuries to the immature brain the various reasons in the prenatal, perinatal, and postnatal period accompanied by dysreflexia, dystonia, intellectual disabilities, visual and hearing impairments, convulsions, language impairments, learning disabilities, and emotional disorders (Shevell and Bodensteiner, 2004). As children with cerebral palsy require more help and health care services than children without disabilities (Young et al., 2007). They have higher health care needs and incidence of disease-related complications (Blackman and Conaway, 2014).

Parenting efficacy means cognitive characteristics and beliefs that play an important role in determining parents' caregiving behavior (Brody et al., 1999). Meanwhile, parenting stress is a type of stress felt from the parenting role; it refers to the difficulty and pressure perceived by parents from parenting their children
(Belt and Abidin, 1996). In other words, parents with a higher level of parenting efficacy try the appropriate coping behaviors (Mash and Johnston, 1983), whereas parents with a high level of stress from parenting are more likely to care their children inappropriately (Abidin, 1990). As children with cerebral palsy experience injuries to their senses, communication, and cognition and have many limitations in their activities of daily living, such as eating, dressing, bathing, and moving (Basaran et al., 2013), caregivers cannot stay apart from such children even for a moment. As they also require continuous rehabilitation and their caregiving needs increase as they get older (Cheshire et al., 2010), caregivers are required to do an increasing number of tasks over time.

Mothers of children with cerebral palsy take full responsibility for parenting as well as monitor their children's various health problems and treatment processes; mothers may feel anxious about their children's prognosis, which make them experience more physical and psychological difficulties compared with mothers of typical children (Lyngsøe et al., 2018). Further, burden of
${ }^{*}$ Corresponding author: Youn-Jung Kim (iD https://orcid.org/0000-0003-4991-0825 College of Nursing Science, Kyung Hee University, 26 Kyunghee-daero,

Dongdaemun-gu, Seoul 02447, Korea

E-mail: yj129@khu.ac.kr

Received: October 2, 2019 / Accepted: November 3, 2019
This is an Open Access article distributed under the terms of the Creative Commons Attribution Non-Commercial License (http://creativecommons.org/licenses/by-nc/4.0/) which permits unrestricted non-commercial use, distribution, and reproduction in any medium, provided the original work is properly cited. 
caring on children with disabilities may have a negative impact on family relationships, and it may be extra burden stress to mothers. A previous study also found that mothers of children with cerebral palsy have a higher level of parenting stress compared with mothers of children without any disease (Britner et al., 2003). Hence, the present study was conducted to apply a Parenting Improvement Efficacy Program (PEIP) to mothers who were primary caregivers of children with cerebral palsy, examine the difficulties they experienced owing to their children's impairments, provide help to such mothers after confirming the effect of the program on parenting efficacy and parenting stress, and explore the relation with social support.

\section{MATERIALS AND METHODS}

\section{Participants}

This study is aimed at the mothers of children who are admitted to the rehabilitation ward and daytime rehabilitation wards of $\mathrm{Na}$ tional Health Insurance Service Ilsan Hospital in Goyang, Korea, and are undergoing rehabilitation treatment from outpatients. In this study, mothers who participated in the survey were selected as the control group by giving general explanation to mothers who are interested in this study but cannot participate in the program.

\section{Experimental design}

The present study was based on a nonequivalent control group pretest-posttest design as a quasi-experimental study that divided participants into two groups (experimental and control) depending on whether or not they received the structured PEIP and then compared parenting efficacy and parenting stress between the two groups. Table 1 provides a schematic representation of this design.

\section{Measurements}

\section{Parenting efficacy scale}

The parenting efficacy scale consists of 37 items in the following five subscales: general parenting, communication, health, education, and control. Before using this scale, this study obtained approval from the author who developed the scale. The parenting

Table 1. Experimental design

\begin{tabular}{lcclccc}
\hline \multirow{2}{*}{ Group } & \multicolumn{2}{c}{ Time 1 } & & \multicolumn{3}{c}{ Time 2 } \\
\cline { 2 - 3 } & Pretest & Posttest & & Pretest & Treatment & Posttest \\
\hline Control (C) & C1 & C2 & & & & \\
Experimental (E) & & & & E1 & $X$ & E2 \\
\hline
\end{tabular}

$X$, program. efficacy scale employed in the present study used a 5-point scale; a higher score indicated a higher level of parenting efficacy. Although this parenting efficacy scale was developed for parents of children who grow over the course of normal development, the present study applied the scale to mothers of pediatric patients with cerebral palsy, because the scale was about general parenting, and not specific academic performance or cognitive ability (Choi et al., 2012).

\section{Parenting stress scale}

To measure the parenting stress of mothers of children with cerebral palsy, this study used the Parenting Stress Index/Short Form (PSI/SF) developed by Abidin (1990) for parents of children at risk of disability aged 1 to 12 years. The PSI/SF consists of 36 items in the three subscales of parental distress, parent-child dysfunctional interaction, and difficult child. The PSI/SF used for mothers in the present study employed a 5-point scale in which 1 point indicated "strongly disagree" and 5 points, "strongly agree." A higher score indicated a higher level of parenting stress, and a lower score indicated a lower level of parenting stress. Before using this scale, this study obtained approval from the author who developed the scale.

\section{Procedure}

PEIP

Focusing on improving parenting efficacy and reducing parenting stress for mothers of children with cerebral palsy, this study established a program that a nurse could directly use in the hospital for mothers of children under rehabilitation for cerebral palsy. Program is incorporating informational support, which included lectures on the need for meetings among mothers of children with cerebral palsy children and the characteristics of children with cerebral palsy, and emotional support, which included sharing stress situations in parenting children with cerebral palsy, finding the causes of stress and self-understanding, finding the strengths of the mother and the child, meditating and stretching, and watching videos on cerebral palsy. In implementing the PEIP for mothers of children with cerebral palsy, one physical medicine and rehabilitation physician, one nursing professor, one chief nurse in the rehabilitation ward, one nurse with more than 5 years of experience in the rehabilitation ward, and one pediatric physiotherapist agreed to the program's contents and methods.

\section{Program intervention}

The above-mentioned health care professionals divided the ex- 
perimental group into three teams and had participated in the program twice per week (Team 1: Monday and Thursday; Team 2: Tuesday and Friday; Team 3: Wednesday and Saturday). The program was provided for five sessions, each for $50 \mathrm{~min}$.

\section{Program procedure}

This program was implemented over five sessions and divided into three stages: Beginning for session 1, middle for sessions 2 to 4 , and end for session 5 . The program's contents were categorized into informational, emotional, and appraisal support. Informational support included lectures on the need for meetings among mothers of children with cerebral palsy and the characteristics of children with cerebral palsy. Emotional support included sharing stressful situations in parenting children with cerebral palsy, finding the causes of stress and self-understanding, finding the strength of the mother and the child, meditating and stretching, and watching videos on cerebral palsy. Appraisal support included listening, empathy, acceptance, and encouragement, which occurred during the program. Table 2 describes each session's topic and activities.

\section{Ethical consideration}

This study was conducted with the permission of the Institutional Review Board (No. 2016-09-005), and the questionnaire completed by the participants in the study will never be used for research purposes. The personal confidentiality and anonymity exposed to the study were fully guaranteed and fully explained that participants could withdraw from the study at any time if desired. In addition, it explained that there are no costs, side effects, and risks involved in participating in the study, and explained the pur-

Table 2. Parenting efficacy improvement program

\begin{tabular}{llc}
\hline Session & \multicolumn{1}{c}{ Activity } & Time \\
\hline Session 1 & - Program guide & 50 min (lecture, \\
& - Participant self-introduction & discussion, \\
& - What is cerebral palsy? & $0 \& \mathrm{~A}$ ) \\
Session 2 & - Sharing the stress of child care with cerebral palsy & 50 min \\
& - Stress causes and self-deflection in child care of & (discussion) \\
& cerebral palsy & \\
& - Find me and the advantage of the child & \\
Session 3 & - Change your thinking (stretching and meditation) & 50 min \\
& & (exercise) \\
Session 4 & - Watch a video on cerebral palsy & 50 min \\
& & (watch video) \\
Session 5 & - Exploring and finalizing pathways for children with & 50 min (lecture, \\
& cerebral palsy & discussion, \\
& - Program summary and evaluation & $0 \& \mathrm{~A}$ )
\end{tabular}

pose and method of research before the program and received the voluntary consent form in writing before the program.

\section{Data analysis}

The data were analyzed by chi-square test, independent t-test, and two-way repeated analysis of variance design using IBM SPSS Statistics ver. 20.0 (IBM Co., Armonk, NY, USA).

\section{RESULTS}

\section{General characteristics}

The general characteristics of this study were as follows. The two groups were homogeneous because there was no statistically significant difference between the experimental and control groups (Table 3).

Table 3. General features of the study subjects $(n=60)$

\begin{tabular}{|c|c|c|c|c|}
\hline Characteristic & Experimental $(n=30)$ & Control $(n=30)$ & $\chi^{2}$ or $t$ & $P$-value \\
\hline Mother age (yr) & & & 0.601 & 0.606 \\
\hline$>35$ & $17(56.7)$ & $14(46.7)$ & & \\
\hline$\leq 35$ & $13(43.3)$ & 16 (53.3) & & \\
\hline Final education & & & 2.009 & 0.571 \\
\hline Below high school & $5(16.7)$ & $7(23.3)$ & & \\
\hline College & $11(36.6)$ & $14(46.7)$ & & \\
\hline University & $12(40.0)$ & $7(23.3)$ & & \\
\hline Graduate school & $2(6.7)$ & $2(6.7)$ & & \\
\hline Job & & & 6.372 & 0.095 \\
\hline Housewife & $16(53.3)$ & $25(83.3)$ & & \\
\hline Part-time job & $2(6.7)$ & $1(3.3)$ & & \\
\hline Self-employment & $7(23.3)$ & $2(.6 .7)$ & & \\
\hline Full-time job & $5(16.7)$ & $2(6.7)$ & & \\
\hline Child gender & & & 1.071 & 0.438 \\
\hline Boy & $14(46.7)$ & $18(60.0)$ & & \\
\hline Girl & $16(53.3)$ & $12(40.0)$ & & \\
\hline Child age (yr) & & & 3.140 & 0.208 \\
\hline$<3$ & $12(40.0)$ & $6(20.0)$ & & \\
\hline $3-7$ & $9(30.0)$ & $14(46.7)$ & & \\
\hline$>7$ & $9(30.0)$ & $10(33.3)$ & & \\
\hline Birth order & & & 3.536 & 0.316 \\
\hline First & $21(70.0)$ & $15(50.0)$ & & \\
\hline Second & $7(23.3)$ & $9(30.0)$ & & \\
\hline Third & $2(6.7)$ & $5(16.7)$ & & \\
\hline Fourth or more & $0(0.0)$ & $1(3.3)$ & & \\
\hline Disability rating & & & 3.140 & 0.208 \\
\hline Yes & $18(60.0)$ & $15(50.0)$ & & \\
\hline No & $12(40.0)$ & $15(50.0)$ & & \\
\hline
\end{tabular}

Values are presented as number (\%). 
Table 4. Difference test on parenting efficacy between experimental group and control group

\begin{tabular}{|c|c|c|c|c|c|}
\hline \multirow{2}{*}{ Group } & \multicolumn{2}{|c|}{ Parenting efficacy } & \multirow{2}{*}{ Source } & \multirow{2}{*}{$F$} & \multirow{2}{*}{$P$-value } \\
\hline & Before & After & & & \\
\hline \multirow{2}{*}{$\begin{array}{l}\text { Experimental } \\
(n=30)\end{array}$} & $93.13 \pm 3.78$ & $163.10 \pm 3.16$ & Group & 39.48 & $<0.001$ \\
\hline & & & Time & 325.99 & $<0.001$ \\
\hline Control $(n=30)$ & $98.93 \pm 3.78$ & $100.63 \pm 3.16$ & Group $\times$ time & 295.79 & $<0.001$ \\
\hline
\end{tabular}

Values are presented as mean \pm standard error.

The experimental group's parenting efficacy increased to a statistically significant level from 93.13 in the pretest to 163.10 in the posttest $(P<0.001)$. Mean difference $=-69.97,{ }^{*} P<0.05$.

\section{Differences in parenting efficacy between the experimental and control groups}

Mothers of children with cerebral palsy under rehabilitation were divided into the experimental group, which received the PEIP. Homogeneity between the two groups was tested, and no statistically significant $(t=-1.09, P=0.283)$.

The posttest difference showed a significant interaction between the groups and the timing, which confirmed a difference in the program's effect between the experimental and control groups $(F=$ 295.79, $P<0.001)$. The control group's parenting efficacy score from 98.93 in the pretest to 100.63 in the posttest, which showed no statistically significant difference $(P=0.547)$. By contrast, the experimental group's parenting efficacy increased to a statistically significant level from 93.13 in the pretest to 163.10 in the posttest $(P<0.001)$ (Table 4).

\section{Differences in parenting stress between the experimental and control groups}

Mothers of children with cerebral palsy under rehabilitation were divided into the experimental group, which received the PEIP. Homogeneity between the two groups was tested, and no statistically significant $(t=1.94, P=0.058)$.

The posttest difference showed a significant interaction between the groups and the timing, which confirmed a difference in the program's effect between the experimental and control groups $(F=138.74$, $P<0.001)$. The control group's parenting stress score from 122.90 in the pretest to 121.37 in the posttest, which showed no statistically significant difference $(P=0.501)$. By contrast, the experimental group's parenting stress decreased statistically significantly from 129.67 in the pretest to 90.43 in the posttest $(P<0.001)$ (Table 5).

\section{DISCUSSION}

The present study provided a PEIP to mothers who were pri-
Table 5. Difference test on parenting stress between experimental group and control group

\begin{tabular}{|c|c|c|c|c|c|}
\hline \multirow{2}{*}{ Group } & \multicolumn{2}{|c|}{ Parenting stress } & \multirow{2}{*}{ Source } & \multirow{2}{*}{$F$} & \multirow{2}{*}{$P$-value } \\
\hline & Before & After & & & \\
\hline \multirow{2}{*}{$\begin{array}{l}\text { Experimental } \\
(n=30)\end{array}$} & $129.67 \pm 2.47$ & $90.43 \pm 2.91$ & Group & 12.17 & $<0.001$ \\
\hline & & & Time & 162.22 & $<0.001$ \\
\hline Control $(n=30)$ & $122.90 \pm 2.47$ & $121.37 \pm 2.91$ & Group $\times$ time & 138.74 & $<0.001$ \\
\hline
\end{tabular}

Values are presented as mean \pm standard error.

The experimental group's parenting stress decreased statistically significantly from 129.67 in the pretest to 90.43 in the posttest $(P<0.001)$. Mean difference $=-39.23$, ${ }^{*} P<0.05$.

mary caregivers for children with cerebral palsy under rehabilitation, and confirmed the effect of the program on improving parenting efficacy and reducing parenting stress. Based on the results of the PEIP the following can be discussed.

First, parenting efficacy improved more in the experimental group, which was provided with the PEIP than in the control group. This effect may be attributed to the better understanding of disease that was shaped by the specific knowledge and information on cerebral palsy during the program. The session for finding strengths in the mother and child in the program helped the mothers overcome negative thoughts and develop positive ones, which could have resulted in improvements in their efficacy. Further, while exploring a career for their children with cerebral palsy, the mothers planned a positive future, stayed away from the thought that they were the only ones who had difficulties, and had opportunities to share how they felt with other mothers of children with cerebral palsy; this may have contributed to improving their parenting efficacy. Self-help groups are recognized as valuable for supporting parents of children with disabilities or chronic diseases that cause a high level of stress (Rahi et al., 2004). It is not easy for mothers of children with disabilities to learn information about parenting their children from people around them. And they feel less confident and scared about parenting their children owing to a lack of awareness and understanding about disabilities, which is consistent with the findings of a previous study that when children with disabilities show unusual behaviors and experience bias or rejection from society, the parenting efficacy of their parents could be lower (Gallagher et al., 1983). The present study found that the mothers accepted their children's disabilities by participating in the program, improved their confidence, trusted their ability in parenting for the years ahead, and enhanced their parenting efficacy.

Second, parenting stress decreased more in the experimental group, which was provided with the PEIP than the control group. 
The reason for this effect seems to be that sharing about stressful situations in parenting children with cerebral palsy and finding the causes of stress and self-understanding in the program may have helped the mothers of children with cerebral palsy share how they felt in group training and reduce their stress. This outcome is particularly meaningful as this intervention reduced their high level of stress, confirming the finding of a previous report that mothers of children with cerebral palsy have a higher level of parenting stress compared with mothers of children without any disease (Britner et al., 2003). In addition, based on a previous study that children with cerebral palsy need more help from caregivers as they have higher health care needs and a higher incidence of disease-related complications (Blackman and Conaway, 2014), the present study found that mothers who spent much of time for parenting their children with cerebral palsy did not have a time left for their self-worth changing thoughts on physical activities in the program (meditating and stretching) taught those mothers who were physically fatigued how to meditate and stretch, which would have had a positive effect on decreasing stress. Similar to our results, many other studies proving the effects of exercise on relieving stress (Dishman and Buckworth, 1996; Dishman et al., 2002; Fleshner, 2005), the program would have had a positive effect on parenting stress directly or indirectly. Mothers' high level of parenting stress could cause a coercive, authoritarian, and rejective parenting attitude (Evans et al., 2008) as such, it would be urgently necessary to find a solution to relieve parenting stress.

Although there have so far been many studies on depression among mothers of children with cerebral palsy (Focht-Birkerts and Beardslee, 2000; Goodman and Gotlib, 1999), few studies have been conducted on parenting efficacy or parenting stress, which are practically required to care children with disabilities. Hence, the present study showed significance as it provided evidence on the importance of coping with parenting efficacy and parenting stress with the parenting training program provided by nurses who met children with cerebral palsy and their mothers in the hospital. This study further offered practical help to mothers who were primary caregivers of children with cerebral palsy under rehabilitation.

\section{CONFLICT OF INTEREST}

No potential conflict of interest relevant to this article was reported.

\section{REFERENCES}

Abidin RR. Introduction to the special issue: the stresses of parenting. J Clin Child Psychol 1990;19:298-301.

Basaran A, Karadavut KI, Uneri SO, Balbaloglu O, Atasoy N. The effect of having a children with cerebral palsy on quality of life, burn-out, depression and anxiety scores: a comparative study. Eur J Phys Rehabil Med 2013;49:815-822.

Belt W, Abidin RR. The relation of childhood abuse and early parenting experiences to current marital quality in a nonclinical sample. Child Abuse Negl 1996;20:1019-1030.

Blackman JA, Conaway MR. Adolescents with cerebral palsy: transitioning to adult health care services. Clin Pediatr (Phila) 2014;53:356-363.

Britner PA, Morog MC, Pianta RC, Marvin RS. Stress and coping: a comparison of self-report measures of functioning in families of young children with cerebral palsy or no medical diagnosis. J Child Fam Stud 2003;12:335-348.

Brody GH, Flor DL, Gibson NM. Linking maternal efficacy beliefs, developmental goals, parenting practices, and child competence in rural single-parent African American families. Child Dev 1999;70:1197-1208.

Cheshire A, Barlow JH, Powell LA. The psychosocial well-being of parents of children with cerebral palsy: a comparison study. Disabil Rehabil 2010;32:1673-1677.

Choi H, Kim M, Park CG, Dancy BL. Parent-child relationships between Korean American adolescents and their parents. J Psychosoc Nurs Ment Health Serv 2012;50:20-27.

Dishman RK, Buckworth J. Increasing physical activity: a quantitative synthesis. Med Sci Sports Exerc 1996;28:706-719.

Dishman RK, Jackson EM, Nakamura Y. Influence of fitness and gender on blood pressure responses during active or passive stress. Psychophysiology 2002;39:568-576.

Evans GW, Boxhill L, Pinkava M. Poverty and maternal responsiveness: the role of maternal stress and social resources. Int J Behav Dev 2008; 32:232-237.

Fleshner M. Physical activity and stress resistance: sympathetic nervous system adaptations prevent stress-induced immunosuppression. Exerc Sport Sci Rev 2005;33:120-126.

Focht-Birkerts L, Beardslee WR. A child's experience of parental depression: encouraging relational resilience in families with affective illness. Fam Process 2000;39:417-434.

Gallagher JJ, Beckman P, Cross AH. Families of handicapped children: sources of stress and its amelioration. Except Child 1983;50:10-19.

Goodman SH, Gotlib IH. Risk for psychopathology in the children of depressed mothers: a developmental model for understanding mechanisms of transmission. Psychol Rev 1999;106:458-490. 
Lyngsøe BK, Vestergaard CH, Rytter D, Vestergaard M, Munk-Olsen T, Bech $\mathrm{BH}$. Attendance of routine childcare visits in primary care for children of mothers with depression: a nationwide population-based cohort study. Br J Gen Pract 2018;68:e97-104.

Mash EJ, Johnston C. Parental perceptions of child behavior problems, parenting self-esteem, and mothers' reported stress in younger and older hyperactive and normal children. J Consult Clin Psychol 1983; 51:86-99.

Rahi JS, Manaras I, Tuomainen H, Hundt GL. Meeting the needs of par- ents around the time of diagnosis of disability among their children: evaluation of a novel program for information, support, and liaison by key workers. Pediatrics 2004;114:e477-482.

Shevell MI, Bodensteiner JB. Cerebral palsy: defining the problem. Semin Pediatr Neurol 2004;11:2-4.

Young NL, Gilbert TK, McCormick A, Ayling-Campos A, Boydell K, Law M, Fehlings DL, Mukherjee S, Wedge JH, Williams JI. Youth and young adults with cerebral palsy: their use of physician and hospital services. Arch Phys Med Rehabil 2007;88:696-702. 